\title{
Ethylene Polymerization Using of Fluorinated FI Zr-based Catalyst
}

\author{
R. Sandaroos, G. H. Zohuri*, S. Damavandi \\ Department of Chemistry, Ferdowsi University of Mashhad, P.O. Box 91775 Mashhad, Iran.
}

\begin{abstract}
A fluorinated FI Zr-based catalyst of Bis[N-(3,5-dicumylsalicylidene)-2',6'-Flouroanilinato]zirconium(IV) dichloride was prepared and used for polymerization of ethylene. It was shown that ortho-F substituted phenyl ring on the $\mathrm{N}$ electronically plays a key point in the suppression of chain transfer reactions especially B-hydride transfer leading to increase the molecular weight and moderation of the catalyst activity as well. Methylaluminoxane (MAO) and triisobuthylaluminum (TIBA) were used as a cocatalyst and a scavenger respectively. Involvement of ortho-F not only increased the activity, but reduced the $[\mathrm{Al}] /[\mathrm{Zr}]$ molar ratio in comparison with the similar non fluorinated FI catalysts. The catalyst showed the maximum activity at about [Al]:[Zr]=32000:1 molar ratio and further addition didn't affect the activity of the catalyst. The highest activity of the prepared catalyst was obtained at $40{ }^{\circ} \mathrm{C}$. At the monomer pressure of 3 bars was obtained polyethylene with the viscosity average molecular weight $(\bar{M} V)$ of $1.3 \times 10^{6}$ indicating the dramatic effect of ortho-F substitution on the polymerization mechanism.
\end{abstract}

Keywords: fluorinated FI catalyst, catalytic polymerization, Zr-based catalyst, olefin polymerization.

\section{Introduction}

FI catalysts have been found to produce various new polymers such as low molecular weight, ethylenepropylene copolymer and ultra high molecular weight PE[1]. In this contribution, we studied syntheses and ethylene polymerization behavior of FI catalyst having fluorine containing ligand. We found that ligand comprising fluor atom effectively impresses the polymerization behavior and the $(\bar{M} V)$ of the obtained polymer as well.

\section{Experimental}

Zirconium tetrachloride, phenol and aniline derivatives and 4-toluenesulfonic acid (Merck, Germany), n-Butyllithium and MAO (Sigma Aldrich Chemicals) were used as received. Ligand preparation, catalyst preparation and ethylene polymerization procedure were carried out under dried $\mathrm{N}_{2}$

\section{Result and discussion}

Polymerization of ethylene using the prepared catalysts (Figure 1) was studied in the different

$[\mathrm{Al}] /[\mathrm{Zr}]$ molar ratio. The optimum activity was obtained at $[\mathrm{Al}]:[\mathrm{Ti}]=32000: 1$ molar ratio. The relatively low ratio of $[\mathrm{Al}]:[\mathrm{Ti}]$ obtained for the catalyst with reasonable activity comparing to this type of FI catalysts could be an advantage of the catalyst. It is important to point out that using the $[\mathrm{Al}] /[\mathrm{Zr}]$ molar ratio more than this value didn't cause a further enhancement in the activity of the catalysts indicating low chain transfer specially Bhydride transfer which is responsible to produce low molecular weight polymer (Figure 2). The behavior could be due to the electronically interaction between $\mathrm{H}_{\beta}$ and ortho $\mathrm{F}$ atom substituted phenyl ring on the $\mathrm{N}$. At the monomer pressure of 3 bars the catalyst could produce polyethylene with the $(\overline{M V})$ of $1.3 \times 10^{6}$ which is high value in comparison of the similar FI catalysts indicating the dramatic effect of ortho-F substitution on the polymerization mechanism. It was proposed that attractive interaction, which is expected to effectively curtail $\mathrm{B}-\mathrm{H}$ transfer to the central metal and incoming monomer, is responsible for the unprecedented behavior [2,3]. However, for ethylene coordination, the transition state of the $\mathrm{B}-\mathrm{H}$ transfer is probably disfavored. This fact was proved with the moderation of activity of the catalyst. The highest activity of the catalyst was $3.2 \times 10^{5} \mathrm{~g} \mathrm{PE} / \mathrm{mmol} \mathrm{Zr}$. h at the temperature of $35{ }^{\circ} \mathrm{C}$ and monomer pressure of 2 bars.

The highest activity of the catalyst was obtained at about $35{ }^{\circ} \mathrm{C}$. The catalytic activity was increased with increasing the temperature from $20{ }^{\circ} \mathrm{C}$ to $35^{\circ} \mathrm{C}$ following to a decrease at higher temperature. An increase in the propagation rate coefficient and also an irreversible deactivation of the catalytic active

*E-mail: zohuri@um.ac.ir 


\section{9th International Seminar on Polymer Science and Technology \\ Iran Polymer and Petrochemical Institute, Tehran, Iran \\ 17-21 October 2009}

sites at high temperature can explain the increase and decrease in activity respectively[4]. Meanwhile solubility of the monomer gas in the polymerization solvent decreased with increasing temperature Activity was slightly increased with the increasing of the monomer pressure (Figure 3).

\section{Conclusion}

A FI catalyst comprised of fluorinated bis(phenoxyimine) $\mathrm{Zr}$ complex was prepared and used for ethylene polymerization. Ortho-F substituted phenyl ring on the $\mathrm{N}$ electronically plays a key point in the suppression of chain transfer reactions especially $B$ hydride transfer leading to increase the molecular weight and moderation of the catalyst activity too. The highest activity of the catalyst and the $\bar{M} V$ of the obtained polymer were $3.2 \times 10^{5} \mathrm{~g} \mathrm{PE} / \mathrm{mmol} \mathrm{Zr}$. h and $1.3 \times 10^{6}$ respectively. Crystallinity and melting point of the obtained polymer were between 60-65 $\%$ and $125-130{ }^{\circ} \mathrm{C}$. The highest activity of the catalyst was obtained at about $35^{\circ} \mathrm{C}$.

\section{References}

1- Fujita, T.; Tohi, Y.; Matsui, S.; Saito, J.; Makio, H.; Tsutsui, T. EP-0874005 Mitsui Chemicals Inc, 1998.

2- Mitani, M.; Mohri, J.; Yoshida, Nakano, Fujita, T. J Am Chem Soc; 124, 3327, 2002.

3- Tian, J.; Hustad, P. D.; Coates, G. W. J Am Chem Soc, 123, 5134, 2001.

4- Busico, V.; Talarico, G.; Cipullo, R.; Macromol Symp, 226, 1, 2005.

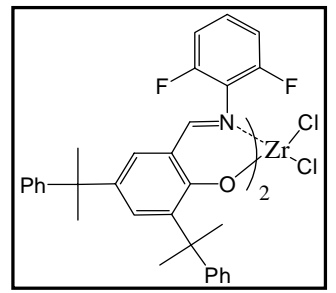

Figure 1. Structure of the catalyst

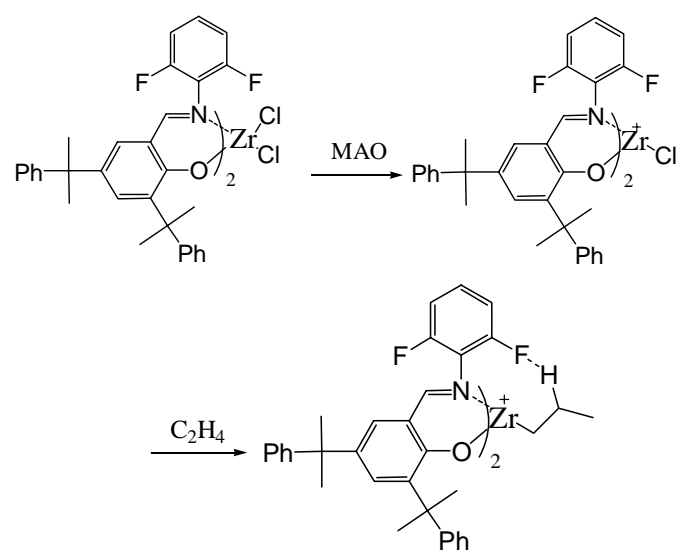

Figure 2. The electronically interaction between $H_{B}$ and ortho F atom substituted phenyl ring

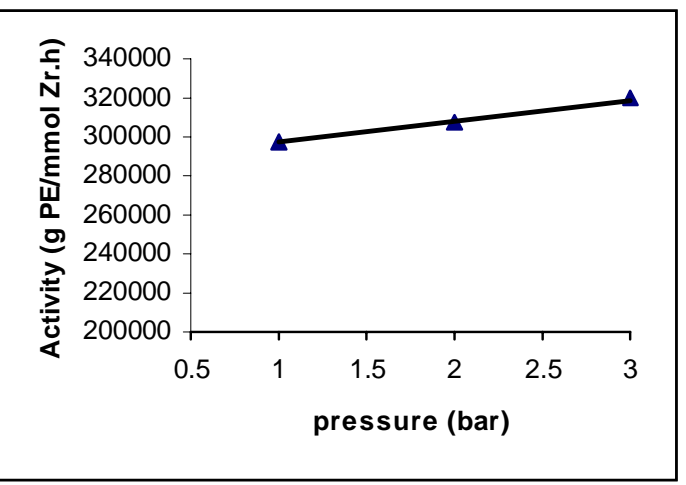

Figure 3. Effect of monomer pressure on the average rate of polymerization. 